\title{
Tecnologias e Educação Profissional: O que dizem os alunos de uma Fábrica de Games?
}

Sthenio José Ferraz Magalhães - PPGEdumatec - UFPE - sthenio@ live.com Patrícia Smith Cavalcante - PPGEdumatec - UFPE - patricia3smith@gmail.com

\section{Resumo}

Esta pesquisa teve como objetivo identificar as contribuições da formação oferecida pelo projeto Fábrica de Games (FG), incorporado às atividades de uma escola pública do ensino médio do Estado de Pernambuco, além de tentar compreender suas especificidades e sua relação com a educação profissional técnica de nível médio. Realizou-se uma pesquisa exploratória de natureza qualitativa, onde foram analisados questionários aplicados aos alunos. Os resultados apontaram que a construção de games estimula nos alunos a criticidade, o protagonismo intelectual, a conscientização e a autonomia, além de indicar que a metodologia de trabalho utilizada é inovadora e agrega ao processo de ensino e aprendizagem situações lúdicas que facilitam a construção do conhecimento. Evidenciamos ainda que as contribuições da FG para a educação profissional técnica de nível médio estão ligadas, principalmente, ao diferencial das formações oferecidas por suas habilitações.

Palavras-chave: ensino médio profissional, desenvolvimento de games, protagonismo juvenil.

\section{Technologies and Professional Education: What students say about a Games Factory?}

\begin{abstract}
The present study has aimed at identifying the contributions of the training offered by the project Games Factory (GF) that has been incorporated to the activities in a public high school of the state of Pernambuco, Brazil. Moreover, it has tried to comprehend their specifications and relations concerning the professional technical education of high school. A qualitative exploratory research was carried out in which questionnaires applied to the students were analyzed. The results have pointed out that the games design and construction stimulate the students intellectual protagonism, autonomy, awareness, as well as help them becoming more critics. The study has also pointed that the methodology of work applied is innovative and aggregates ludic situations to the process of teaching-learning which facilitate the knowledge building. We have also highlighted that the contributions of the GF for the professional technical education in high school are connected, specially, to the differential offered by their courses through the trainings.
\end{abstract}

Keywords: professional high school, games development, young protagonism.

\section{Introdução}

Os avanços tecnológicos têm alcançado cada vez mais notoriedade por apresentar à sociedade constantes inovações que acabam alterando a conjuntura do dia- 
a-dia dos seus usuários, tais como telefones, cada vez mais portáteis e multitarefa; instrumentos cirúrgicos, rotineiramente aperfeiçoados e com proposta de aumentar a eficiência e diminuir os efeitos invasivos; eletrodomésticos, incorporando características funcionais e práticas; computadores, incrivelmente menores, mais leves, personalizáveis e financeiramente acessíveis. Todas elas desafiam (em escalas diferentes) os novos usuários a entenderem o seu funcionamento e a transitarem com propriedade no mundo digital.

Nesse contexto, a escola, enquanto instituição que constrói, sistematiza e socializa o conhecimento, assume a tarefa de contextualizar as demandas da nova ordem econômica e social com as práticas exercidas em seu interior. Em especial, as escolas de educação profissional técnica de nível médio são incumbidas de preparar cidadãos para atuar num mundo regido pelo conhecimento, onde precisam dominar habilidades que permitam assimilar e utilizar produtivamente recursos tecnológicos novos e em acelerada transformação (BRASIL, 2007).

Diante disso, o Oi Futuro', em parceria com a Secretaria de Educação do Governo de Pernambuco, implantou um Núcleo Avançado em Educação (Nave) na Escola de Referência em Ensino Médio (EREM) Cícero Dias no intuito de oferecer aos alunos, além da formação no ensino médio, disciplinas necessárias para a introdução na cultura digital como, por exemplo: programação de games, criação de conteúdo para TV digital, desenvolvimento de roteiros interativos, criação e manipulação de som e imagem, entre outras. $\mathrm{O}$ pioneirismo do projeto no que se refere à inserção das tecnologias digitais no cotidiano escolar, de maneira integrada ao currículo formal da escola, nos incita a questionar quais as contribuições do desenvolvimento de games para a educação profissional técnica de nível médio.

Dessa forma, analisamos o projeto Fábrica de Games (FG), da EREM Cícero Dias, com o objetivo de identificar as contribuições da sua formação a partir das significações dos alunos, além de compreender suas especificidades e sua relação com a educação profissional técnica de nível médio. Para tal, buscamos responder às seguintes questões norteadoras: Quais atividades são desenvolvidas na FG? Qual a sua relação com os conteúdos da formação em nível médio? Em que medida o projeto FG contribui com a educação profissional técnica?

Neste ínterim, buscamos reunir elementos que permitam o avanço nas discussões sobre o uso possível das tecnologias digitais na escola e sua inserção no contexto da educação profissional técnica, tendo como lócus uma experiência institucional específica de desenvolvimento de games digitais.

\section{Contexto}

Dos tempos em que o conhecimento era transmitido oralmente, passando pelo advento do livro como forma estática de socializar o saber, até a popularização do computador pessoal (e todos os seus periféricos, redes virtuais e mídias) o mundo passou por diversas mudanças no que tange às formas de apropriação e compartilhamento dos saberes.

A escola não esteve alheia a este movimento, se apropriando, num ritmo bem particular, de algumas dessas novas ideias a fim de reelaborar sua forma de conceber o ensino e a aprendizagem na tentativa de garantir a efetivação dos seus propósitos. O advento das novas tecnologias da informação e comunicação (NTICs) desperta uma série de questionamentos arraigados nesse contexto ao propor modificações na estrutura de ensino formal pautadas nas possibilidades de trabalho colaborativo, interativo $\mathrm{e}$ significativo, uma vez que permitem, entre outras coisas, a conexão simultânea dos 
diversos sujeitos envolvidos no processo educativo a uma mesma rede, em momentos síncronos ou assíncronos, sugerindo uma nova relação com os conceitos de contexto, espaço e tempo. Em paralelo, estudos recentes passaram a se interessar pela associação games-educação e suas implicações, teorizando, por exemplo, sobre os estilos de aprendizagem dos nativos digitais ${ }^{2}$, as habilidades desenvolvidas em atividades dessa natureza e o impacto das diversas possibilidades do uso de games em educação (ALVES, 2007; 2008; GEE, 2008; LI, 2010; PRENSKY, 2006).

Debruçar-nos sobre a experiência da EREM Cícero Dias oportuniza perceber de que maneira esses aspectos se articulam, no contexto da educação profissional técnica de nível médio, onde as novas tecnologias digitais parecem ser incorporadas com mais facilidade por conta das exigências da sua grade curricular. Por ser uma escola de ensino médio com proposta de horário integral, todos os alunos do $1^{\circ}$ ao $3^{\circ}$ ano passam o período da manhã e tarde em atividades que dão conta tanto do ensino regular quanto do ensino técnico.

O currículo da FG está organizado de modo a contemplar suas duas habilitações: Programação para Jogos Digitais e Artes para Jogos Digitais. No $1^{\circ}$ ano, além de um bloco comum, os alunos cursam uma disciplina de cada habilitação, permitindo que tenham contato com práticas e técnicas específicas de programação e artes para jogos digitais, além de oportunizar a compreensão dessas qualificações, para que no ano seguinte optem por se aprofundar em uma delas. A partir do $2^{\circ}$ ano o currículo passa a contemplar disciplinas específicas da área escolhida, além das comuns às duas habilitações, como ilustra a tabela 1.

Tabela 1 - Divisão geral de disciplinas da FG

\begin{tabular}{|c|c|c|}
\hline \multicolumn{3}{|c|}{$\begin{array}{l}\text { DISCIPLINAS COMUNS ȦS HABILITAÇÖES EM ARTES E PROGRAMAÇĀO DA } \\
\text { FÁBRICA DE GAMES }\end{array}$} \\
\hline $1^{\circ}$ ANO & $2^{\circ} \mathrm{ANO}$ & $\mathbf{3}^{0} \mathrm{ANO}$ \\
\hline Cultura de Jogos Digitais & $\begin{array}{l}\text { Ofícina de Criação de Jogos } \\
\text { Analógicos }\end{array}$ & $\begin{array}{l}\text { Orientação/acompanhamento } \\
\text { de Estágio III }\end{array}$ \\
\hline Introduçãoà Informática & $\begin{array}{l}\text { Arquitetura das Plataformas de } \\
\text { Jogos Digitais }\end{array}$ & $\begin{array}{l}\text { Projeto Integralizador III - } \\
\text { Concebendo Jogos }\end{array}$ \\
\hline Lógica de Programação & Legislação e Ética Profissional & $\begin{array}{l}\text { Estágio Supervisionado (não } \\
\text { obrigatório) }\end{array}$ \\
\hline Arte para Jogos Digitais & $\begin{array}{l}\text { Orientação/acompanhamento de } \\
\text { Estágio II }\end{array}$ & \\
\hline $\begin{array}{l}\text { Empreendedorismo e } \\
\text { Negócios em Jogos Digitais }\end{array}$ & $\begin{array}{l}\text { Projeto Integralizador II- } \\
\text { Transformando Jogos }\end{array}$ & \\
\hline $\begin{array}{l}\text { Orientação/acompanhamento } \\
\text { de Estágio I }\end{array}$ & $\begin{array}{l}\text { Ofícina de Criação de Jogos } \\
\text { Analógicos }\end{array}$ & \\
\hline $\begin{array}{l}\text { Projeto Integralizador I- } \\
\text { Copiando Jogos }\end{array}$ & $\begin{array}{l}\text { Arquitetura das Plataformas de } \\
\text { Jogos Digitais }\end{array}$ & \\
\hline
\end{tabular}

Essas disciplinas possuem bases (tecnológicas, científicas ou instrumentais) e itinerários pedagógicos muito particulares, indicados no Plano de Curso, destacando a pesquisa, a experimentação e a análise de características das diversas plataformas de jogos digitais através de projetos desenvolvidos em equipe, onde os alunos são responsáveis pelo desdobramento das atividades e o professor assume o papel de problematizador e provocador, no intuito de relacionar os fundamentos teóricos à prática.

\subsection{Sociedade do Conhecimento Digital e o Ensino com Tecnologias}

No contexto da Sociedade da Informação, caracterizada pelo poder que a informação tem na contemporaneidade, gerenciar o grande volume de conhecimento 
disponível, filtrando o que é relevante, representa um desafio. As competências ligadas a essa capacidade de gerenciamento, atreladas ao dinamismo e flexibilidade, foram rapidamente incorporadas às exigências do mercado de trabalho, que passou a buscar mão-de-obra qualificada distinguida por aptidões como liderança, responsabilidade e disponibilidade para trabalhar em grupo.

O sistema educacional, tentando se alinhar a este paradigma, tenta incluir práticas demandadas pela cibercultura, que é definida por Lévy como sendo "um conjunto de técnicas (materiais e intelectuais), de práticas, de atitudes, de modos de pensamento e de valores que se desenvolvem juntamente com o crescimento do ciberespaço", entendido como um novo meio de comunicação que surge da interconexão mundial dos computadores (1999, p. 17).

Os jovens, por manusearem constantemente as tecnologias digitais, conhecem bem seu potencial e suas especificidades, estabelecendo uma relação híbrida entre a cultura e a tecnologia que desafia seus professores a ressignificarem seu modus operandi. Esse movimento favorece a inclusão de atividades mais contextualizadas e interativas nas salas de aula, próximas das proposições de Alves (2008) ao defender a presença do lúdico nas situações de aprendizagem por meio, por exemplo, da utilização de games.

\subsection{Educação Profissional e Novas Tecnologias da Informação e Comunicação}

A educação profissional técnica possui novas resoluções legais que inscrevem um caráter mais humano à sua formação quando integra o ensino técnico ao ensino médio. $\mathrm{O}$ sentido de ensino médio integrado, como indica o documento que regulamenta a Educação Profissional Técnica de Nível Médio, expressa

uma concepção de formação humana, com base na integração de todas as dimensões da vida no processo educativo, visando à formação omnilateral dos sujeitos. Essas dimensões são o trabalho, a ciência e a cultura (BRASIL, 2007, p. 40-41).

Essas afirmações rompem com a ideia de que a educação profissional trata apenas da transmissão de técnicas, em detrimento da formação humana do cidadão. Percebe-se no documento que regulamenta a Educação Profissional Técnica de Nível Médio uma concepção de educação integrada, pressupondo que a educação geral se torne indissociável da educação profissional em todos os campos onde se dá a preparação para o trabalho: seja nos processos produtivos ou nos educativos (BRASIL, 2007).

No fomento dessas experiências que preparam os jovens para os desafios do meio profissional, as novas tecnologias digitais favorecem o trabalho em grupo, estimulam a criação, colaboração e integração de todos os sujeitos nos projetos desenvolvidos durante o processo de aprendizagem. Esse processo colaborativo de aprendizagem, tal como afirma Kenski (2003), presume a interdependência do grupo e está mais relacionado ao desenvolvimento das competências dos alunos para trabalharem em equipes do que unicamente o domínio de conteúdos.

Como exemplo do movimento atual nas salas de aula, as pesquisas de Tapscott (1999) indicam que os jovens, frequentes usuários das novas tecnologias digitais, passaram a propor formas inovadoras de aprendizagem caracterizadas pela dinâmica participativa e pela horizontalidade das relações de poder na sala de aula, pautando as ações na autonomia, nos interesses mútuos e na colaboração. Essas propostas refletem o desejo de remodelar a educação no sentido de agregar valores atuais, alinhados com as 
vivências culturais contemporâneas, reagindo contra as estruturas arcaicas e ultrapassadas da escola. Porém, é necessário um profundo conhecimento das metodologias de ensino e dos processos de aprendizagem para que essas novas experiências não sejam superficiais e nem se limitem ao modismo (KENSKI, 2003).

Numa sociedade onde o conhecimento se tornou a principal força produtiva da contemporaneidade, passível de renovações e expansões rápidas, manter-se atualizado se faz importante. A escola precisa flexibilizar suas práticas para valorizar situações permeadas por atividades significativas com vistas ao aperfeiçoamento das competências dos seus alunos, considerando aspectos da cibercultura que podem tornála o espaço de todas as vozes.

\subsection{Games e educação}

O empenho de educadores e pesquisadores na busca por novas metodologias aplicadas ao processo de ensino e aprendizagem tem apontado a necessidade de abordagens mais interativas e imersivas, onde o aprendiz é estimulado a construir seu próprio conhecimento a partir da experimentação, facilitada pelos diversos ambientes virtuais disponíveis (ALVES, 2007).

Alves (2008) indica que os games, por serem meios tecnológicos capazes de empregar o elemento lúdico na construção do conhecimento, facilitam aprendizagens significativas ao propor experiências que se aproximam do universo semiótico dos alunos, além de associar à escola o sentido de "espaço de prazer".

$\mathrm{Na}$ interação com os diversos tipos de games, os usuários imergem em realidades virtuais diferentes das que vivenciam no mundo real, o que requer algum nível de abstração e pensamento crítico para resolver as situações-problema postas em cena. Pecchinenda 2003 citado por Alves 2008 trás o conceito de "homo game" para ilustrar a integração entre o console, o software, a mente que joga e o jogador, num movimento hibrido onde o que conta é ser comunicativo.

Para além do ato de jogar, pesquisas como as de Li (2010) começam a desvelar as contribuições da produção de games para a aprendizagem, destacando que a educação para o século XXI deve valorizar a cultura participativa e repensar o ensino e aprendizagem em tempos de web 2.0. Em seus resultados pôde observar o sentimento positivo dos sujeitos da pesquisa relacionado à proposta, além de sugerir que a criatividade, o engajamento $\mathrm{e}$ as novas identidades foram os traços marcantes apresentados pelos participantes na aprendizagem a partir da construção de games. Evidencia, ainda, que os estudantes aumentaram a sua compreensão a cerca do assunto tratado pelo game produzido e reforçaram sua capacidade geral de resolução de problemas durante o processo.

Os games exigem uma postura ativa de mobilização cognitiva mediante reflexão, que demanda formar associações a fim de se chegar a uma solução. Moratori (2003) lista algumas dessas aptidões cognitivas e emocionais arregimentadas pelos games: concentração, tomada de decisões, lidar com derrotas e vitórias, analisar situaçõesproblema na sua amplitude, elaborar estratégias, propor soluções, entre outras.

\section{Design Metodológico}

Esta pesquisa teve natureza exploratória em função de não haver estudos precedentes sobre o projeto $\mathrm{FG}$, no âmbito da educação, empreendendo uma primeira aproximação com os fenômenos relacionados ao objeto de estudo (MARCONI \& LAKATOS, 2007). Também se caracterizou como estudo de caso por estar interessada especificamente na EREM Cícero Dias, única escola estadual do Ensino Médio em 
Pernambuco que possui implementado o projeto FG, configurando um caso particular com múltiplos aspectos globais a serem investigados.

Os dados foram coletados através de um questionário composto por cinco questões abertas pré-elaboradas, sistemática e sequencialmente organizadas em seções que objetivaram identificar as significações dos alunos com relação à participação nas atividades desenvolvidas na FG, as aprendizagens decorrentes, suas contribuições e a relação com o mercado de trabalho. Optamos por questões abertas por permitirem aos entrevistados discorrer livremente sobre os assuntos postos, fornecendo informações fidedignas baseadas nas suas experiências.

Foram enviados trinta questionários aos alunos por meio de correio eletrônico, sendo esta uma opção metodológica alinhada com a intenção dos pesquisadores de incluir tecnologia em pesquisas que se interessam por tecnologias, além de ser uma ferramenta amplamente difundida que possibilita interação direta com os sujeitos.

Para o tratamento dos dados foi utilizada uma abordagem qualitativa organizada em três momentos: redução dos dados, onde os dados obtidos foram selecionados e simplificados; categorização, que consistiu na organização que subsidiou a análise; e a interpretação dos dados, onde foram descritos e analisados, permitindo compreender criticamente o sentido das comunicações (GIL, 2002).

\section{Análise e Discussão dos Resultados}

Dos trinta questionários enviados, obtivemos a resposta de três sujeitos. Refletindo a perspectiva de uma pesquisa qualitativa, que está mais interessada nos significados das ações e relações humanas do que em critérios numéricos, tomamos esses três retornos como uma amostra que consegue apresentar algumas nuances das significações dos alunos da FG concatenadas aos objetivos desta pesquisa, sem impor generalizações e considerando a pluralidade de opiniões existente.

\subsection{Perfil dos alunos}

O Aluno T é do sexo masculino, tem 21 anos de idade e se formou no ano de 2009. As alunas C e R são do sexo feminino, no momento da aplicação cursavam o $2^{\circ}$ ano e têm 15 e 16 anos de idade, respectivamente. Os três sujeitos informaram morar na região metropolitana do Recife.

\subsection{O trabalho Discente na Fábrica de Games}

As respostas aos questionários revelaram impressões positivas que os discentes têm do curso, estando ligadas à importância da área profissional em questão e à possibilidade de expressar sua criatividade com liberdade nas atividades da Fábrica de Games.

Quando perguntados sobre qual o papel que desempenhavam nas equipes de desenvolvimento dos games e o que faziam, listaram suas funções atribuindo a elas toda a importância na cadeia produtiva de um game, demonstrando o engajamento e a organização do trabalho desenvolvido pelos alunos. Como exemplo, destacamos os seguintes trechos:

Game desing e Level desing, as duas pontas fundamentais de um jogo. No game, é a questão de elaboração do jogo, histórias, personagem e outros. E no level, a montagem do jogo, na questão de organização de cenários e grau de dificuldade do jogo (ALUNO T, 2010). 
Sou ilustradora, e além disso coordeno meu grupo em suas atividades (ALUNA C, 2010).

Gerenciar os projetos, distribuir o tempo e produzir trabalhos relacionados à ilustração e design (ALUNA R, 2010).

Percebemos aí aspectos da discussão teórica de Kenski (2003) no que diz respeito ao trabalho colaborativo e em grupo, à organização dos papéis desempenhados e à integração dos alunos nos projetos desenvolvidos durante as situações de aprendizagem. É notória a participação ativa dos discentes nas atividades e a opção predominante do trabalho em equipe, fator principal indicado por Kenski (2003) para o desenvolvimento de processos colaborativos de aprendizagem.

Além disso, os interrogados demonstraram em suas respostas ter aprendido o processo de produção profissional de games.

\subsection{Relação entre o projeto FG e o currículo do Ensino Médio}

No que tange à integração da FG com as disciplinas clássicas do currículo, considerando suas contribuições, percebemos que as habilidades específicas ampliadas no desenvolvimento de games ajudam nas disciplinas do ensino regular (como o desenho, para artes, e programação, para Matemática) e contribuem com aspectos ligados à esfera atitudinal (como o trabalho em equipe e a racionalização do tempo).

Para ilustrar, selecionamos os seguintes trechos:

Pode-se aprimorar em várias áreas, desde artes, com um desenho que tem suas tonalidades e traços, até a sua programação que envolve muitos cálculos matemáticos (ALUNO T, 2010).

Nós aprendemos, sobretudo, a nos organizarmos. Isto é o que todos os educadores do técnico ensinam, pois um game passa por várias etapas para ser desenvolvido (ALUNA C, 2010).

Organização do tempo e o trabalho em grupo (ALUNA R, 2010).

Lévy (1999) considera essa abordagem ampla do currículo, com disciplinas que conseguem se interpenetrar e, através do diálogo, gerar aprendizado para a vida. Os currículos da FG e do Ensino Médio seguem esta linha, sendo desenvolvidos de forma integrada e conseguindo estabelecer diálogo entre as diversas atividades desenvolvidas. As respostas dadas pelos alunos conseguem expressar tal afirmação e demonstram como isso acontece na prática.

A necessária organização e seleção qualitativa do grande número de informações veiculadas diariamente também são discutidas por Lévy (Ibid.) e parecem ser vivenciadas pelos discentes da FG, uma vez que as variáveis "organização" e "foco no trabalho a ser desenvolvido" são apresentadas nos trechos anteriormente destacados.

Com relação às aprendizagens listadas a partir da construção de games, identificamos que estas estavam ligadas à área técnica do curso, como o manuseio de programas específicos e o refinamento do olhar relacionado ao processo de criação de um game, além de aspectos de ordem subjetiva, como organização e disponibilidade para o trabalho em equipe, como podemos perceber nas falas destacadas:

O que você aprendeu criando games?

V. $9 \mathrm{~N}^{\mathrm{o}}$ 2, dezembro, 2011 
Primeiramente, trabalho em equipe, que é o mais difícil, devido as diferentes maneiras de pensar. Habilidades com vários programas de construção de um jogo, que vai de um simples desenho ao som de todo jogo. Ponto de vista diferente, de não mais ver o jogo como uma diversão, por outro lado de pensar com sí só - como é que foi feito essas coisas. Com um olhar crítico que se adquiriu com o passar do ano (ALUNO T, 2010).

Aprendi que criar jogos não é tão simples como muitas pessoas pensam, envolve muitas partes e muita responsabilidade e temos que aprender a lidar com uma equipe, organizar as idéias de todos. No começo não gostava do curso pois era cansativo, mas hoje já me "divirto" aprendendo. (ALUNA C, 2010).

O trabalho em grupo, que é uma peça importantíssima para um bom desenvolvimento do trabalho, aprender a distribuir o tempo e se organizar, para entregar nos prazos e que criar jogos não é uma tarefa fácil, porém prazerosa (ALUNA R, 2010).

Essas considerações estão alinhadas com as pesquisas desenvolvidas por $\mathrm{Li}$ (2010) no Canadá, apontando que a produção de games no contexto da educação é bem aceita pelos adolescentes e proporciona momentos significativos de aprendizagem, com estímulo à criatividade e engajamento dos sujeitos. Também valida as colocações de Alves (2008) ao demonstrar que, quando bem fundamentada, a presença de elementos lúdicos na sala de aula é capaz de ajudar na construção do conhecimento e tornar ações pedagógicas mais dinâmicas e prazerosas, próximas do contexto cultural dos alunos.

As respostas dadas pelos sujeitos também nos permitem inferir que, durante os estudos para estruturar da melhor forma o game a ser construído, o assunto tratado é melhor compreendido e envolto de significados que lhes atribuem valor.

\subsection{FG e o mundo do trabalho}

No que diz respeito ao mercado de trabalho ligado às habilitações da FG, os dois sujeitos que estavam em processo de conclusão do curso acreditam que terão mais chances por conta da formação que estão recebendo. O terceiro sujeito, aluno egresso, indicou que a sua formação não contribuiu para que conseguisse um emprego, mas justificou argumentado que no decorrer do curso não deu atenção às disciplinas que, no futuro, percebeu serem as mais exigidas pelos empregadores. Sobre isso, selecionamos os seguintes excertos:

O que aprendi não me ajudou a arrumar trabalho porque eu não segui a carreira por completo. Tive certa resistência em algumas matérias na questão do aprendizado. Coisas que no meu pondo de vista, durante o curso não eram necessárias, e hoje são as principais. Rola um certo arrependimento (ALUNO T, 2010).

Ainda não trabalhei pois estou cursando o $2^{\circ}$ ano e como a escola é em tempo integral, não há tempo. Entretanto, no ano que vem talvez surgirão propostas para estágio, mas com certeza irá ajudar a arrumar um trabalho sim (ALUNA C, 2010). 
Ainda estou em processo de conclusão do curso, mas vejo que terei mais chances com a capacitação que estou recebendo (ALUNA R, 2010).

A fala dos alunos demonstra a integração do ensino profissional ao ensino médio e consegue materializar o que regulamenta o documento oficial que versa sobre a Educação Profissional Técnica de Nível Médio, propondo uma educação integrada onde a educação geral está associada à profissional, perpassando a formação humana do sujeito.

As respostas das alunas $\mathrm{C}$ e $\mathrm{R}$ exemplificam a receptividade daqueles que ainda estão em formação, com expectativas favoráveis à entrada no mercado de trabalho por conta da formação oferecida durante o Ensino Médio.

Já o depoimento do Aluno $\mathrm{T}$ demonstra a realidade vivenciada por parte dos alunos oriundos do curso, que por se tratar de uma experiência única, não possuía referência para servir de parâmetro. Dá margem a afirmarmos que as disciplinas elencadas no Plano de Curso da FG se estruturam em eixos contínuos e complementares que dão uma noção ampla do campo de atuação do profissional habilitado, onde a falta de uma delas pode interferir na qualidade do trabalho do profissional diplomado.

Numa análise mais ampla, identificamos aspectos ligados a uma nova educação emergente, discutida por Lévy (1999), que nas suas práticas envolvem pesquisa, criação e construção do conhecimento em processos educativos que levam em consideração o preparo do cidadão para atuar num mundo regido pela informação, com competência para assimilar e utilizar proficientemente as novas tecnologias.

\section{Conclusões}

O ensino médio integrado à educação profissional preconiza um projeto que agregue à formação geral formações profissionais, regido por um currículo que valorize a reflexão crítica da sociedade e do mundo do trabalho e prepare seus alunos para serem sujeitos na construção do conhecimento. A organização curricular da FG dá indícios que o ensino e a pesquisa são valorizados pela EREM Cícero Dias, estimulando nos seus alunos, por meio da construção de games, a criticidade, o protagonismo intelectual, a conscientização e a autonomia diante do trabalho.

As contribuições da FG para a Educação Profissional Técnica de Nível Médio estão ligadas ao diferencial das formações oferecidas por suas habilitações, apresentando aos jovens possibilidades de qualificação na promissora área de produção de games.

Além disso, percebemos que a integração do seu conteúdo com o currículo do ensino regular favorece um melhor desempenho nas atividades de ambos, que passam a se complementar enquanto repertório cultural. Os saberes clássicos abordados no ensino regular dão subsídios ao trabalho no curso técnico - por exemplo, um game que está ambientado na Era Medieval certamente necessitará de conhecimentos ligados às disciplinas de História e Geografia - e as atividades na FG desenvolvem habilidades aproveitadas por disciplinas clássicas, como a Matemática nas aulas de programação de games.

Sua metodologia de trabalho é inovadora e integra o uso das tecnologias digitais à sala de aula por meio de uma proposta contextualizada e significativa, agregando ao movimento de ensino e aprendizagem situações lúdicas que facilitam a construção do conhecimento. Reforça aspectos relacionados à subjetividade dos alunos quando sugere a realização dos trabalhos em equipe, estimula a criatividade e o engajamento, incita $o$ protagonismo, além de exigir organização e disciplina. 
A inserção dos alunos oriundos no mercado de trabalho merece ser mais discutida em pesquisas futuras com enfoque específico, que disponham de uma amostra variada de sujeitos, porém, de antemão podemos afirmar que existe em Pernambuco um nicho de mercado promissor a ser explorado pelos habilitados na $\mathrm{FG}$, onde os empregadores buscam por pessoal com as qualificações ali oferecidas.

Assim, concluímos que este curso adéqua-se às normas do Ministério da Educação e amplia a formação discente, constituindo cidadãos mais preparados para a vida e para o trabalho.

\section{Notas}

${ }^{1}$ Instituto de responsabilidade social da empresa de telecomunicações Oi.

2 Termo criado por Marc Prensky para caracterizar aqueles que já nasceram e cresceram na era das tecnologias digitais.

\section{Referências}

ALVES, L. Nativos digitais: games, comunidades e aprendizagens. In: MORAES, Ubirajara Carnevale de. (org.). Tecnologia educacional e aprendizagem: o uso dos recursos digitais. Livro Pronto: São Paulo, 2007, p. 233-251.

- Relações entre os jogos digitais e aprendizagem: delineando percurso. In: Educação, Formação \& Tecnologias. vol. 1. n. 2. p. 3-10, nov. 2008.

BRASIL, Ministério da Educação. Documento Base da Educação Profissional Técnica de Nível Médio Integrada ao Ensino Médio. Brasilia: MEC/SETEC, nov. 2007.

GEE, J. Why Are Video Games Good For Learning?. Madison WI: MacArthur Foundation - University of Wisconsin, [ca. 2008].

GIL, A. C. Como elaborar projetos de pesquisa. 4.ed. São Paulo: Atlas, 2002.

KENSKI, V. M. Aprendizagem mediada pela tecnologia. Revista Diálogo Educacional, Curitiba, v. 4, n.10, p.47-56, set./dez, 2003.

LÉVY, P. Cibercultura. Trad. Carlos Irineu da Costa. São Paulo: Ed. 34, 1999.

LI, Q. Digital game building: learning in a participatory culture. Educational Research, Volume 52, Issue 4, 2010.

MARCONI, M. A.; LAKATOS, E. M. Fundamentos de metodologia científica. 6.ed. São Paulo: Atlas, 2007.

MORATORI, P. Por que utilizar jogos educativos no processo de ensino aprendizagem?. 2003. 28f. Trabalho de conclusão da disciplina Introdução a Informática na Educação (Mestrado de Informática aplicada à Educação) - Instituto de Matemática, UFRJ, Rio de Janeiro.

PERNAMBUCO, Secretaria de Educação. Plano de Curso: curso técnico de nível médio em programação de jogos digitais. Escola de Referência em Ensino Médio Cícero Dias, mar, 2009. 
PRENSKY, M. Don't Bother Me, Mom, I'm-Learning! How computer and video games are preparing your kids for 21st century success and how you can help!. St Paul: Paragon House Publishers, 2006.

TAPSCOTT, D. Geração Digital: a crescente e irreversível ascensão da Geração Net. São Paulo: Makron Books do Brasil, 1999. 